\title{
Cryptocurrencies: market analysis and perspectives
}

\author{
Giancarlo Giudici $^{1} \cdot$ Alistair Milne $^{2} \cdot$ Dmitri Vinogradov $^{3,4}$
}

Received: 7 September 2019 / Revised: 7 September 2019 / Accepted: 11 September 2019 /

Published online: 17 September 2019

(c) Associazione Amici di Economia e Politica Industriale 2019

\begin{abstract}
The papers in this special issue focus on the emerging phenomenon of cryptocurrencies. Cryptocurrencies are digital financial assets, for which ownership and transfers of ownership are guaranteed by a cryptographic decentralized technology. The rise of cryptocurrencies' value on the market and the growing popularity around the world open a number of challenges and concerns for business and industrial economics. Using the lenses of both neoclassical and behavioral theories, this introductory article discusses the main trends in the academic research related to cryptocurrencies and highlights the contributions of the selected works to the literature. A particular emphasis is on socio-economic, misconduct and sustainability issues. We posit that cryptocurrencies may perform some useful functions and add economic value, but there are reasons to favor the regulation of the market. While this would go against the original libertarian rationale behind cryptocurrencies, it appears a necessary step to improve social welfare.
\end{abstract}

Keywords Cryptocurrencies · Cryptoassets · Bitcoin · Blockchain

JEL Classification G30 - E42

Dmitri Vinogradov

Dmitri.Vinogradov@glasgow.ac.uk

Giancarlo Giudici

giancarlo.giudici@polimi.it

Alistair Milne

A.K.L.Milne@lboro.ac.uk

1 Politecnico di Milano, Milan, Italy

2 University of Loughborough, Loughborough, UK

3 University of Glasgow, Glasgow, UK

4 National Research University Higher School of Economics, Russian Federation, Perm, Russia 


\section{Introduction}

Cryptocurrencies continue to draw a lot of attention from investors, entrepreneurs, regulators and the general public. Much recent public discussions of cryptocurrencies have been triggered by the substantial changes in their prices, claims that the market for cryptocurrencies is a bubble without any fundamental value, and also concerns about evasion of regulatory and legal oversight. These concerns have led to calls for increased regulation or even a total ban. Further debates concern inter alia: the classification of cryptocurrencies as commodities, money or something else; the potential development of cryptocurrency derivatives and of credit contracts in cryptocurrency; the use of initial coin offerings (ICO) employing cryptocurrency technology to finance start-up initiatives; and the issue of digital currencies by central banks employing cryptocurrency technologies.

These discussions often shed more heat than light. There is as yet little clearly established scientific knowledge about the markets for cryptocurrencies and their impact on economies, businesses and people. This special issue of the Journal of Industrial and Business Economics aims at contributing to fill this gap. The collection of papers in the special issue offers six distinct perspectives on cryptocurrencies, written from both traditional and behavioural viewpoints and addressing both financial questions and broader issues of the relationship of cryptocurrencies to socio-economic development and sustainability.

Here in this introduction we set the stage by defining and discussing the main concepts and issues addressed in the papers collected in this special issue and previewing their individual contributions. Cryptocurrencies are digital financial assets, for which records and transfers of ownership are guaranteed by a cryptographic technology rather than a bank or other trusted third party. They can be viewed as financial assets because they bear some value (discussed below) for cryptocurrency holders, even though they represent no matching liability of any other party and are not backed by any physical asset of value (such as gold, for example, or the equipment stock of an enterprise). ${ }^{1}$

As the word cryptocurrency, and the other terminology employing 'coin', 'wallets' in the original whitepaper proposing the supporting technology for Bitcoin (Nakamoto 2008) all suggest, the original developers consciously attempted to develop a digital transfer mechanism that corresponded to direct transfer of physical cash used for payments or other financial assets- such as a precious metals and 'bearer bonds' - that like cash also change hands through physical transfer.

What about the arrangements used for financial assets recorded in digital form (such as bank deposits, equities or bonds but not bearer bonds or bank notes)? Ownership arrangements for these assets depend on the information system maintained by a financial institution (commercial bank, custodian bank, fund manager) determining who is entitled to any income or other rights it offers and has the right of sale or transfer. Originally these systems were paper based, but since the 1960s they have

\footnotetext{
${ }^{1}$ From the accounting perspective, cryptocurrencies are investment assets, sometimes even treated similarly to stocks for accounting purposes (Raiborn and Sivitanides 2015).
} 
utilised first mainframe and more recently computer systems. ${ }^{2}$ If there is a shortcoming in their information system, for example a breach of security that leads to theft or loss or failure to carry out an instruction for transfer, then the financial institution is legally responsible for compensating the owner of the asset.

In the case of cryptocurrencies, it is the supporting software that both verifies ownership and executes transfers. ${ }^{3}$ There is no requirement for a 'trusted third party'. This approach though requires a complete historical record of previous cryptocurrency transfers, tracing back each holding of cryptocurrency to its initial creation. This historical record is based on a "blockchain", a linking of records ("blocks") to each other in such a way that each new block contains information about the previous blocks in the growing list ("chain") of digital records. So that every participant in the cryptocurrency network sees the same transaction history, a new block is accepted by agreement across the entire network.

The applications of this technology are not necessarily finance-related; it can be applied to any form of record-keeping; however if the block refers to a financial transaction then each transaction in the blockchain, by definition, includes information about previous transactions, and thus verifies the ownership of the financial asset being transferred. Falsifying ownership, i.e. counterfeiting (which, one could imagine, is easy, as digital objects can be easily duplicated by copying), is impossible because one would have to alter preceding records in the whole chain. Since records are kept in the network of many users' computers, a "distributed ledger", this is rather unthinkable.

There is a substantial computer science literature on the supporting cryptocurrency technologies, including on the security of public key cryptography, efficient search tools for finding transactions on the blockchain, and the 'consensus' mechanisms used to establish agreement on ledger contents across the network. ${ }^{5}$ Commentators expect new more efficient approaches will replace the mechanisms currently used in Bitcoin and other cryptocurrencies. ${ }^{6}$ This though would not affect

\footnotetext{
2 Milne (2015) provides a history of the information systems used in securities markets.

3 A more detailed yet still accessible overview of the key features of the current technology behind cryptocurrencies can be found in Böhme et al. (2015). Narayanan et al. (2016) provide a detailed textbook description. A key feature is that ownership is identified with a public cryptographic key. The matching private cryptographic key can then be used both to confirm ownership of the associated public key and to instruct transfers of the cryptocurrency to other public keys. The number of these keys is effectively unlimited. In the case of Bitcoin these keys are 256-bit binary numbers, so in consequence there are $2^{256}$ possible public keys; an almost unimaginably large number.

4 Third parties may still play a role in the functioning of a cryptocurrency. For example, $5 \%$ of XRP, the cryptocurrency that supports Ripple international payments platform is held by Ripple themselves, and their decisions to buy or sell affect market supply. Third parties also support stablecoins such as Tether or Facebook's proposed Libra currency.

5 Blockchains are validated and updated within peer-to-peer networks using a 'consensus mechanism' (for example "proof of work" or "proof of stake", see Tschorsch and Scheuermann 2016) that prevents members of the network from creating a false version of history. This consensus then supports a fully decentralized secure verification of ownership and exchange (Pilkington 2016; Goldstein et al. 2019). In the case of Bitcoin, the term block was originally used because its consensus mechanism ('mining') is applied to append 'blocks' of around 1000 transactions at a time to the chain of transaction records.

${ }^{6}$ For a review of several prominent consensus mechanisms see Baliga (2017).
} 
our definition of cryptocurrencies (as an asset and some technology which verifies ownership of the asset), which is independent of any particular technological implementation. $^{7}$

Cryptocurrencies can be seen as part of a broader class of financial assets, "cryptoassets" with similar peer-to-peer digital transfers of value, without involving third party institutions for transaction certification purposes. What distinguishes cryptocurrencies from other cryptoassets? This depends on their purpose, i.e. whether they are issued only for transfer or whether they also fulfil other functions. Within the overall category of cryptoassets, we can follow the distinctions drawn in recent regulatory reports, distinguishing two further sub-categories of cryptoassets, on top of cryptocurrencies: ${ }^{8}$

1. Cryptocurrencies: an asset on a blockchain that can be exchanged or transferred between network participants and hence used as a means of payment—but offers no other benefits.

Within cryptocurrencies it is then possible to distinguish those whose quantity is fixed and price market determined (floating cryptocurrencies) and those where a supporting arrangement, software or institutional, alters the supply in order to maintain a fixed price against other assets (stable coins, for example Tether or the planned Facebook Libra).

2. Crypto securities: an asset on a blockchain that, in addition, offers the prospect of future payments, for example a share of profits.

3. Crypto utility assets: an asset on a blockchain that, in addition, can be redeemed for or give access to some pre-specified products or services.

A further distinguishing feature of crypto securities and crypto utility assets is that they are issued through a public sale (in so called initial coin offerings or ICOs). ICOs have been a substantial source of funding for technology orientated start-up companies using blockchain based business models. These classifications of cryptoassets are critical for global regulators, since they need to determine whether a particular cryptoasset should be regulated as an e-money, as a security or as some other form of financial instrument, especially in relation to potential concerns about investor protection in ICOs. ${ }^{9}$

\footnotetext{
7 Ripple (XRP) is an example of a cryptoasset that does not use blockchain. However, it has a different purpose designed primarily to mediate conversions from currency to currency, or from any asset A to asset B.

${ }^{8}$ For example (Bank of England, Financial Conduct Authority, and HM Treasury 2018; ESMA 2019; EBA 2019) and also (Hacker and Thomale 2017). The term 'token' is often used as a shorthand reference to cryptoassets, especially for crypto securities and crypto utility assets (e.g. Adhami and Guegan 2020), though Milne (2018) argues that this usage can be misleading, disguising similarities with more conventional financial assets.

9 Recent discussion of these issues includes FSB (2018), FCA (2019) and Blandin et al. (2019).
} 
Table 1 List of cryptocurrencies with market capitalization above \$1bn as of 26 August 2019 (Source: http://www.coinmarketcap.com)

\begin{tabular}{llccrl}
\hline$\#$ & Name & \multicolumn{1}{l}{ Market Cap } & \multicolumn{1}{l}{ Price } & \multicolumn{1}{l}{ Volume $(24 \mathrm{~h})$} & Circulating supply \\
\hline 1 & Bitcoin & $\$ 184,544,558,521$ & $\$ 10,311.21$ & $\$ 17,873,581,752$ & $17,897,462$ BTC \\
2 & Ethereum & $\$ 20,516,368,996$ & $\$ 190.89$ & $\$ 6,874,655,939$ & $107,475,882$ ETH \\
3 & XRP & $\$ 11,653,569,398$ & $\$ 0.271585$ & $\$ 1,128,653,524$ & $42,909,539,227$ XRP \\
4 & Bitcoin cash & $\$ 5,591,057,154$ & $\$ 311.17$ & $\$ 1,340,301,589$ & $17,967,738$ BCH \\
5 & Litecoin & $\$ 4,689,355,041$ & $\$ 74.30$ & $\$ 2,781,009,887$ & $63,114,962$ LTC \\
6 & Binance coin & $\$ 4,087,419,033$ & $\$ 26.28$ & $\$ 175,001,868$ & $155,536,713$ BNB \\
7 & Tether & $\$ 4,057,931,416$ & $\$ 1.00$ & $\$ 19,899,745,246$ & $4,049,107,372$ USDT \\
8 & EOS & $\$ 3,368,394,232$ & $\$ 3.63$ & $\$ 1,597,861,289$ & $929,024,131$ EOS \\
9 & Bitcoin SV & $\$ 2,398,713,217$ & $\$ 134.34$ & $\$ 295,102,323$ & $17,854,986$ BSV \\
10 & Monero & $\$ 1,402,906,280$ & $\$ 81.68$ & $\$ 111,521,420$ & $17,174,622$ XMR \\
11 & Stellar & $\$ 1,326,874,823$ & $\$ 0.067573$ & $\$ 122,814,593$ & $19,636,142,641$ XLM \\
12 & Cardano & $\$ 1,285,561,035$ & $\$ 0.049584$ & $\$ 105,303,516$ & $25,927,070,538$ ADA \\
13 & UNUS SED LEO & $\$ 1,199,562,655$ & $\$ 1.20$ & $\$ 6,782,406$ & $999,498,893$ LEO \\
14 & TRON & $\$ 1,181,766,594$ & $\$ 0.017722$ & $\$ 508,503,418$ & $66,682,072,191$ TRX \\
\hline
\end{tabular}

Market Cap is the total value of cryptocurrency in circulation at the market price (Price) of the reporting day. Volume is the total volume of transaction in the cryptocurrency in the last $24 \mathrm{~h}$. Circulating Supply is the nominal amount of cryptocurrency in circulation

Floating cryptocurrencies account for the very large majority of the cryptoasset market capitalisation (Tether, a stablecoin, and Bitfinex's UNUS SED LEO, a utility coin, are in the top 12 cryptoassets by market capitalisation, all the rest are floating cryptocurrencies). Table 1 summarises the market share of leading cryptocurrencies at the time of writing.

What is the value of cryptocurrencies? On the one hand, cryptocurrencies should be able to ease financial transactions through elimination of the intermediaries, reduction of transaction costs, accessibility to everyone connected to the Internet, greater privacy and security (see, e.g., discussions in Böhme et al. 2015; Richter et al., 2015). ${ }^{10}$ On the other hand, the real economic value transferred in the transactions of freely floating cryptocurrencies such as Bitcoin's BTC and Ethereum's Ether remains unclear. Despite the exhaustive and unfalsifiable record of all previous transactions held cryptographically, as in the Bitcoin blockchain, the information only refers to nominal numbers, i.e. the amount of cryptocurrency units transferred. One can, however, get an idea of the market value of cryptocurrencies by looking at their exchange rates against existing fiat currencies. This is possible thanks to cryptocurrency exchanges, which provide a nearly continuous price record for all actively traded cryptocurrencies. Although the resulting exchange rates are highly

\footnotetext{
${ }^{10}$ Note that transactions in cryptocurrencies are subject to such restrictions as the lack of reversibility, i.e. an erroneous transaction cannot be cancelled as soon as it is written in the block. More traditional payment systems, such as bank transfers and credit card payments, are more flexible in this respect.
} 
volatile, they reveal that cryptocurrencies have a non-zero value for those prepared to pay fiat currency in order to purchase them.

What drives this value in the absence of a backing asset or an issuer's liability? Some advocate it is the cost of "mining" (energy and time spent on computational efforts required to complete formation of a new block in the chain, and rewarded by a newly issued cryptocurrency unit), however the cost borne by one member of the network does not justify the value of the new cryptocurrency unit for other members of the network (see also Dwyer 2015, who argues the cost of mining is sunk and as such should be disregarded in the market value analysis). Others claim their market value is driven by the speculative bubble; yet, strictly speaking, the bubble is manifested in upward price deviations from the fundamental value (see, e.g., Siegel 2003 , for a review of definitions), hence the bubble explanation is only partial and raises further questions about what drives investors' beliefs that feed their demand and thus support the bubble.

If it is the ease and the speed of transactions, then new transaction technologies and fund transfer systems that greatly improved in the recent decade (such as Transferwise and similar systems) should have wiped out a big chunk of the cryptocurrency value, yet this does not seem to be the case. A possible answer may lie in the features that distinguish cryptocurrencies from other assets and payment systems. Privacy, or rather anonymity, is a prominent distinctive feature popping up in most discussions of cryptocurrencies. The value of a cryptocurrency is then effectively a measure of how much users value anonymity of their transactions. While anonymity may be attractive for illegal activities (and some research reviewed below suggests cryptocurrencies are often used for these purposes), one cannot rule out users may simply wish more privacy, trying to avoid the "Big Brother" effect of traditional transactions. Of course, there may be other factors, for example, fashion (users want to use the technology others are talking about), hi-tech appeal (the desire to use the most modern technology) or curiosity (the desire to try something new), among others, but these phenomena appear shorter-lived than the allure of anonymity.

A key development in the rise of cryptocurrencies and other cryptoassets has been the emergence of cryptoexchanges where anyone can open accounts and trade cryptoassets both against each other and against fiat currencies. In a survey by Hileman and Rauchs (2017), the US dollar, the Euro and the British Pound are currently most widely traded against cryptocurrencies, while the importance of the Chinese Renminbi (CNY) significantly diminished after the tightening of the regulation by the People's Bank of China; about three-quarters of large exchanges provide trading support for two or more cryptocurrencies. Above, we highlighted that cryptoexchanges provide extensive cryptocurrency pricing and trading information in the public domain. The emergence of these exchanges has created an entire 'ecosystem' of services and participants, seeking to provide liquidity, exploit price discrepancies for profit and to support investment by both retail and professional investors.

Academic interest in cryptocurrencies started to soar in 2014 (see Fig. 1): the Scopus database lists 127 publications containing the word 'Bitcoin' in the title or abstract or keywords and 24 containing 'cryptocurrency' or 'cryptocurrencies' in 2014. In 2017 and especially in 2018 the number of publications grew fast, and in 2019 the trend is continuing. Interestingly, academic work focuses much more on 


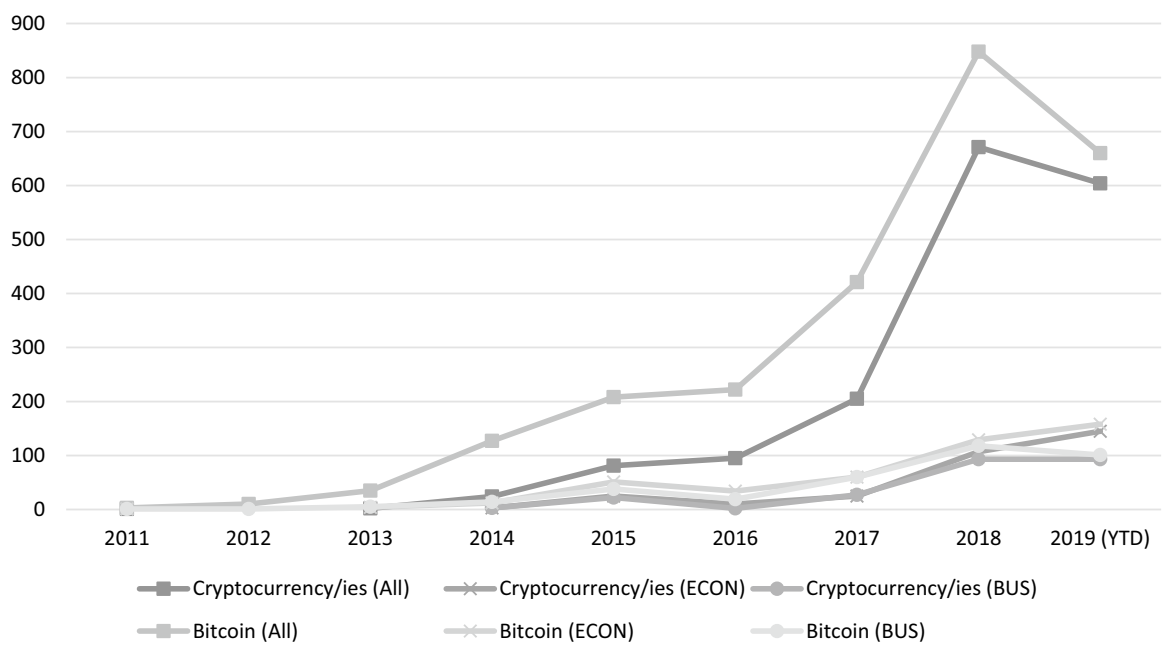

Fig. 1 Publications listed on the Scopus database containing 'Cryptocurrency/ies' and 'Bitcoin' in the title or abstract or keywords. The graph reports the number of publications tracked by the Scopus database (http://www.scopus.com) accessed on August 10, 2019 containing the words "Cryptocurrency/ies" or "Bitcoin" in the title or abstract or keywords. The subsample ECON refers to the category Economics, Econometrics \& Finance while the subsample BUS refers to Business, Management \& Accounting

the Bitcoin than on the more general topic of cryptocurrencies, although in 2018 and in 2019 the gap narrowed. It appears that - apart from the Bitcoin frenzy - there is a growing attention to the general phenomenon of cryptocurrencies. However, focusing only on the 'Economics, Econometrics \& Finance' and 'Business, Management $\&$ Accounting' sections of Scopus reveals that the interest in the topic surged a few years later ${ }^{11}$, although the number of publications is still rather low: in 2018 there were just over 100 titles on the topic in the above fields. The remaining contributions come from the 'Computer Science', 'Engineering' and 'Mathematics' disciplines.

This special issue of the Journal of Industrial \& Business Economics offers a multifaceted view on the cryptocurrency phenomenon. Contributions have been selected with the objective to extend the existing knowledge about cryptocurrencies, which themselves embody innovations and technological change, and may appear to be a lucrative form of fund raising for small businesses; extra emphasis is made on areas of the journal's particular interest, such as environment, sustainability and

\footnotetext{
${ }_{11}$ This delay may also reflect slower publication process in our field, with most papers going through a few not so fast rounds of revisions (let alone rejections) before they get published. Huisman and Smits (2017) review recent evidence on the duration of the publication process; their sample shows, for example, that tit takes twice as long to publish in Economics than, e.g. in Medicine, with an average first response time in Economics and Finance being 16-18 weeks (comparable to Azar's 2007, estimate of 3-6 months). Their sample does not account for the number of previous rejections though. John Cochrane witnesses most of his publications were rejected 2-3 times before getting eventually published (https://johnhcochrane.blogspot.com/2017/09/a-paper-and-publishing.html); further anecdotal evidences are in Shepherd (1995).
} 
social responsibility. The remainder of this editorial proceeds as follows. In Sect. 2 we describe the contributions that shed light on the relationship between cryptocurrencies and financial investments. In Sect. 3 we focus on behavioral issues, while in Sect. 4 we introduce the development of the socio-economic perspectives related to cryptocurrencies and discuss initial coin offerings as a potential source of funds for small businesses. Finally, Sect. 5 concludes discussing the research agenda for the future.

\section{Cryptocurrencies and neoclassical finance}

Cryptocurrencies can be used both as a means of payment and as a financial asset. Glaser et al. (2014) provide evidence that, at least for the Bitcoin, the main reason to purchase a cryptocurrency is speculative investment. Financial securities, such as ETNs (exchange traded notes) and CFDs (derivative products) that replicate Bitcoin's price performance are made available by brokers, expanding the speculative investment opportunities to an even larger set of investors. With this in mind, it makes sense to evaluate cryptocurrencies as financial assets.

The cross-section of cryptocurrency returns has been analyzed in a number of papers. Urquhart (2016) shows that Bitcoin returns do not follow random walk, based on which he concludes the Bitcoin market exhibits a significant degree of inefficiency, especially in the early years of existence. Corbet et al. (2018)analyze, in the time and frequency domains, the relationship between the return of three different cryptocurrencies and a variety of other financial assets, showing lack of relationship between crypto- and other assets. Liu and Tsyvinski (2018) investigate whether cryptocurrency pricing bears similarity to stocks: none of the risk factors explaining movements in stock prices applies to cryptocurrencies in their sample. Moreover, movements in exchange rates, commodity prices, or macroeconomic factors of traditional significance for other assets play little to none role for most cryptocurrencies. The latter invalidates the view on cryptocurrencies as substitutes to monies, or as a store of value (like gold), and rather stresses they are assets of their own class. The review of the literature in Corbet et al. (2019) summarizes the most interesting findings on the role of cryptocurrencies as a credible investment asset class and as a valuable and legitimate payment system.

The relative isolation of cryptocurrencies from more traditional financial assets suggests cryptocurrencies may offer diversification benefits for investors with short investment horizons. Bouri et al. (2017) as well as Baur et al. (2018) find that Bitcoin is suitable for diversification purposes as its returns are uncorrelated with those of most major assets. Interestingly, they provide empirical evidence of the predominant usage of Bitcoins as speculative assets, though this is done on the data on USD transactions only and thus likely reflects the behavior of U.S. cryptocurrency investors mainly. Relatedly, Adhami and Guegan (2020) find that similarly to cryptocurrencies, cryptotokens are also a useful diversification device though not a hedge.

One way to understand similarities and differences between cryptocurrencies and more traditional financial assets is to estimate relationships known for traditional assets. A pattern that has received a lot of attention in the finance literature is the 
co-movement of the trading volume and returns/volatility of financial assets (a by far non-exhaustive list of examples would include Admati and Pfleiderer (1988), Foster and Viswanathan (1993), and Andersen (1996) — for equity markets; Bessembinder and Seguin (1993)_for futures; notably, no clear evidence of such a relationship exists for currencies, i.e. for exchange rates, see, e.g. Côté 1994). This special issue includes a contribution by Figà-Talamanca (2020), who, inter alia, investigate this relationship for cryptocurrencies, along with the impact of "relevant events", which are key disruptive changes to the market infrastructure. They find that Bitcoin trading volume does not affect its returns but detect a positive effect of Bitcoin trading volumes on return volatility. While their focus is mainly on market attention, these results highlight similar forces rule cryptocurrency markets and those for more traditional financial assets, again supporting the view of cryptocurrencies as investment assets. $^{12}$

The risk of holding cryptocurrencies is discussed in this special issue by Fantazzini and Zimin (2020). Cryptocurrency prices may drop dramatically because of a revealed scam or suspected hack, or other hidden problems. For example, on June 26th, 2019, the Bitcoin price lost more than $10 \%$ of the value in a few minutes because of the crashes and outages of the Coinbase digital exchange. As a consequence, a cryptocoin may become illiquid and its value may substantially decline. Fantazzini and Zimin (2020) propose a set of models to estimate the risk of default of cryptocurrencies, which is back-tested on 42 digital coins. The authors make an important point in extending the traditional risk analysis to cryptocurrencies and making an attempt to distinguish between market risk and credit risk for them. The former, as typical in the finance literature, is associated with movements in prices of other assets. The latter is associated in traditional finance with the failure of the counterparty to repay, but as cryptocurrencies presume no repayments, defining credit risk for them is tricky. The authors' approach is to see the "credit" risk of cryptocurrency in the possibility of them losing credibility among users, and thus becoming value-less, or "dead". The authors find, notably, that the market risk of cryptocurrencies is driven by Bitcoin, suggesting some degree of homogeneity in the cryptomarket. As for the credit risk, the traditional credit scoring models based on the previous month trading volume, the one-year trading volume and the average yearly Google search volume work remarkably well, suggesting indeed a similarity between the newly defined credit risk for cryptocurrencies and the one traditionally used for other asset classes.

\section{Cryptocurrencies and behavioral finance and economics}

A large strand of the literature explains market phenomena that work against the neo-classical predictions, from the perspective of unquantifiable risk, or ambiguity. Most commonly, ambiguity is associated with the impossibility to assign

\footnotetext{
12 "Similar forces" here does not mean similar factors: like Liu and Tsyvinski (2018), Figà-Talamanca (2020) find a strong dependence of cryptocurrency returns of their past values, which distinguishes them from other asset classes.
} 
probability values to events that may or may not occur. In the case of cryptocurrencies, this type of uncertainty may arise for two reasons: (1) the technology is rather complicated and opaque to unsophisticated traders, and (2) the fundamental value of cryptocurrencies is unclear. As we highlighted above, even if it is strictly positive, it is likely to derive from intangible factors and as such is rather uncertain. Dow and da Costa Werlang (1992) demonstrate that under pessimism (ambiguity aversion) uncertainty about fundamentals leads to zero trading in financial markets, yet this does not seem to apply to cryptocurrencies. In Vinogradov (2012) not only does the no-trade outcome depend on the degrees of optimism and pessimism, which may vary, but it also manifests only under high risk (in the standard sense). Still, again, although cryptocurrency returns exhibit high volatility, trade volumes are significant. In Caballero and Krishnamurthy (2008) uncertainty leads to "flights to quality" in traditional asset markets, which, if properly applied to cryptocurrencies, might also explain the crashes we recently observed.

Obtaining information is crucial to reduce uncertainty. Figà-Talamanca (2020) focus on a rather general definition of the demand for information, as manifested in the google search index. According to them, the intensity of the internet search for cryptocurrency-related keywords significantly affects cryptocurrency volatility (but not return); this impact vanishes once one controls for "relevant events". These relevant events are effectively announcements of either restrictions (and even bans) on cryptocurrency usage, or of the widening of the cryptocurrency market. While we remain largely agnostic regarding what people find when they search for cryptocurrency related terms on the Internet, the events give us an indication of the type of information that actually matters for cryptocurrency investment decisions, and hence for pricing. In uncertainty, when finding relevant information is uneasy, investors might resort to watching and mimicking other, presumably better informed, investors' decisions, resulting in herding (Trueman 1994; Devenow and Welch 1996), addressed in this special issue by Haryanto et al. (2020), see below.

Uncertainty and attitudes to it are not the only reasons why neoclassical predictions may fail. Shiller (2003) notes that market participants are humans and can make irrational systematic errors contrary to the assumption of rationality. Such errors affect prices and returns of assets, creating market inefficiencies. Studies in behavioral economics highlight inefficiencies, such as under- or overreactions to information, as causes of market trends and, in extreme cases, of bubbles and crashes. Such reactions have been attributed to limited investor attention, overconfidence, mimicry and noise trading, explanations of many of which find roots in Kahneman and Tversky's (1979) prospect theory, which postulates that decision makers evaluate outcomes from the perspective of their current endowment (and are predominantly loss-averse) and "revise" probabilities of outcomes when making decisions (predominantly overweighting probabilities of bad outcomes and underweighting those of good ones). The loss-aversion led Shefrin and Statman (1985) to formulate the 'disposition effect' in investment decisions: investors in traditional assets tend to keep assets that lose value too long and sell those that gain in value too early. 
Three features distinguish cryptocurrency markets: investors are non-institutional, risk (volatility of returns) is high, and the fundamental value is unclear. Under these conditions behavioral biases should be even more pronounced than in traditional asset markets. In this special issue Haryanto et al. (2020) study the disposition effect and the herding behavior in the cryptocurrency realm by investigating the trading behavior at a cryptoexchange: they find a reverse disposition effect in bullish periods where the Bitcoin price increases while a positive disposition effect is observed in bearish periods. They also find that in different market conditions herding moves along with market trend (in the bullish market a positive market return increases herding, while in the bearish market a negative market return has the same effect). The reverse disposition effect in the bullish market indicates investors exhibit more optimism and expect returns to further grow, which is consistent with the exponential price growth in a bubble in the absence of a clearly defined fundamental value. This lack of clarity regarding the fundamental value is also supported by the asymmetric herding behavior: when the price grows in a bullish market, investors look at other market participants to see whether others also think the price will continue to grow (similarly but with the opposite sign for the bearish market).

This special issue also contributes to the debate on the existence of a 'bubble' in the cryptocurrency market (see Baek and Elbeck 2015; Cheah and Fry 2015). The contribution by Moosa (2020) highlights that the Bitcoin was in a bubble up to the end of 2017. The analysis claims that the volume of trading in Bitcoin can be explained predominantly in terms of price dynamics considering past price movements, particularly positive price changes, and that the path of the price is well described by an explosive process.

\section{Socio-economic perspectives}

Critiques emphasize cryptocurrencies are not exempt from frauds and scandals. For example, several millions in Bitcoin from the Japanese platform Mt. Gox in 2014 and \$50 million in Ether during the Decentralized Autonomous Organization (DAO) attack in 2016 were stolen. Moreover, cryptocurrency payments, being largely unregulated, do not restrict any purchases, including those illegal. Böhme et al. (2015) provide summary data showing that, at least in the beginning of the Bitcoin era, most transactions were used for drug purchases. Foley et al. (2019) estimate that about $46 \%$ of Bitcoin transactions are associated with illicit activities, but that the illegal share of Bitcoin activity declined over time with the emergence of more opaque cryptocurrencies. On top of that, users appear unprotected as payments are often irreversible, and an erroneous transfer cannot be cancelled, unlike credit card payments (Böhme et al. 2015).

On the positive side, the development of the cryptocurrency market contributes to the dynamics of access to finance (Adhami et al. 2018). The advent of the blockchain technology allowed entrepreneurial teams to raise capital in cryptocurrencies and fiat money (which has to be exchanged into a cryptocurrency) through the issuance of digital tokens (Initial Coin Offerings, ICOs) and the development of 'smart contracts' (Giudici and Adhami 2019). Tokens give their buyers a right 
to use certain services or products of the issuer, or to share profits, in which case they resemble equity. Special cryptoexchanges then serve the secondary market for tokens. The OECD (2019) lays out basic principles and typical steps of an ICO. An important distinction between tokens and cryptocurrencies is though that there is a liability or some sort of commitment behind the token, and this liability determines its value. Now that this cryptoasset bears more similarity with traditional assets, one would expect also the main predictions of neoclassical finance to come true. In fact, in a recent empirical study of cryptotokens, Howell et al. (2018) demonstrate the effects of asymmetric information on tokens trading: their liquidity and trading volume are positively associated with the information inflow. The latter is achieved through voluntary disclosure of information (including the operating budget and their business plans), and quality signaling (e.g. information on prior venture capital funding of the issuer).

Cryptocurrencies, which underlie the ICO procedure, are claimed to provide much more equitable and democratic access to capital as well as greater efficiency, compared to fiat money, allowing peer-to-peer transactions and avoiding the intermediation of banks (Nakamoto 2008; Karlstrøm 2014). This is normally done via an ICO, and could be a relevant opportunity for small business, which often experience a gap in funding and miss competences to relate with professional investors (Giudici and Paleari 2000). OECD (2019) also reports ICOs are a potential route for low cost finance for SMEs.

Will cryptocurrencies favor a process of "democratization" of funding? This has been widely discussed by practitioners and investors, with a great variety of views. For example, The World Economic Forum White Paper (WEF 2018), claims that cryptocurrencies and blockchain technologies could increase the worldwide trading volume, moving to better levels of service and lower transaction fees. To this extent, the contribution by Ricci (2020) in this special issue considers the geographical network of Bitcoin transactions in order to discover potential relationships between Bitcoin exchange activity among countries and national levels of economic freedom. The study shows that high levels of freedom to trade internationally, that guarantee low tariffs and facilitate international trade, are strongly connected to the Bitcoin diffusion. On the one hand, the freedom to trade internationally could increase the foreign trade through the use of alternative payment instruments capable of reducing transaction costs (like cryptocurrencies), on the other, low capital controls could encourage the use of cryptocurrencies for illegal conduct, such as money laundering.

The reward system for cryptocurrency 'miners' creates an incentive to leverage on computing power, increasing the consumption of energy. For example, Böhme et al. (2015) note that computational efforts of miners are costly, mainly because the proof-of-work calculations are "power-intensive, consuming more than 173 megawatts of electricity continuously. For perspective, that amount is ... approximately $\$ 178$ million per year at average US residential electricity prices." The sustainability topic is raised in this special issue by Vaz and Brown (2020). They posit that there are significant sustainability issues in the cryptocurrency development exceeding potential benefits, that are captured typically by a few people. Therefore, they call for different institutional models with government and public engagement, as to avoid that the market is driven mostly by private money and profit motivations. 


\section{Conclusions}

Growing attention has been paid to cryptocurrencies in the academic literature, discussing whether they are supposed to disrupt the economy or are a speculative bubble which could crash and burn or favor money laundering and criminals. In support of the first view, it is often argued they meet a market need for a faster and more secure payment and transaction system, disintermediating monopolies, banks and credit cards. Critics, on the other hand, point out that the unstable value of cryptocurrencies make them more a purely speculative asset than a new type of money.

The reality is somewhere in between these two positions, with cryptocurrencies performing some useful functions and hence adding economic value, and yet being potentially highly unstable. The trend is towards a regulation of cryptocurrencies, and more generally of all crypto-assets, and to their increased trading on organized and regulated exchanges. This would go against the original libertarian rationale that originated the Bitcoin but is a necessary step to provide protection for market participants and reduce moral hazard and information asymmetries.

How will future research build on the articles in this special issue and on other recent studies of cryptocurrencies? It is of course always difficult to anticipate substantial future research contributions, especially in relation to such a recent and novel phenomenon like cryptocurrencies. But we would argue that there are a few major issues that deserve continued attention from scholars in finance, economics and related disciplines.

One is the need for a much closer examination of the 'market microstructure' of cryptoexchanges. Some recent research already draws attention to the functioning of cryptoexchanges. For example, Gandal et al. (2018) investigate price manipulations at the Mt. Gox Bitcoin exchange; a notable by-product of their research is the finding that suspicious trading on one exchange led to equal price changes on other exchanges, suggesting traders can effectively engage in arbitrage activities across exchanges. Similarly, signs of efficiency are detected in Akyildirim et al. (2019) who investigate pricing of Bitcoin futures on traditional exchanges-Chicago Mercantile Exchange (CME) and the Chicago Board Options Exchange (CBOE). Importantly, in their study information flows and price discovery go from futures to spot markets, in contrast to previous results for traditional assets; a likely explanation is the difference in the type of traders at cryptoexchanges (that determine the spot price) and both $\mathrm{CME}$ and $\mathrm{CBOE} .{ }^{13}$ Yet more has to be learnt about cryptoexchanges. Their open nature distinguishes them from conventional stock exchanges and dealer markets with transactors directly accessing the market rather than relying on brokers as intermediaries. Is this open nature helpful, providing greater liquidity and narrowing trading spreads? Or does it disadvantage some investors, limiting regulatory oversight and allowing a core of participants to manipulate market prices at the expense of other investors? Do the technical arrangements supporting cryptoexchanges, notably the use of distributed ledger or blockchain technology which eliminates the need

\footnotetext{
13 Interestingly, CBOE futures present an informational advantage over the CME alternative, possibly because of the smaller size of contracts and hence the larger number of investors actively trading.
} 
for post-trade settlement, lead to more efficient trading outcomes in terms of price, liquidity and speed of execution? Could these technologies also improve the efficiency of outcomes in conventional financial exchange?

The second issue, widely debated in the cryptocurrency literature, is whether cryptocurrencies have a fundamental own value. Dwyer (2015) conjectures the limitation of the quantity produced can create an equilibrium in which a digital currency has a positive value: this limitation is a form of commitment, replacing the implicit obligation of Central banks to exchange fiat money into gold. Hayes (2017) advocates the cost of production view on cryptocurrency pricing; yet, as we discussed earlier, from a market equilibrium perspective, being sunk cost (as in Dwyer 2015), it does not matter for the pricing of existing coins. ${ }^{14}$ A concurrent work by Bolt and Van Oordt (2019) outlines three key elements of the cryptocurrency value: convertibility into fiat money or ability to buy goods and services, investors' expectations, and factors that determine acceptance of the cryptocurrency in the future, by both vendors and buyers. Simultaneously, Schilling and Uhlig (2019) offer a model where cryptocurrencies are a reliable medium of exchange and compete against fiat money: this role implies the current price of cryptocurrencies is the expectation of their future value (a martingale), yet interestingly, competition and substitutability between the two imply in their analysis cryptocurrencies should disappear in the long run equilibrium. The authors admit that their analysis abstracts away such distinctive features of cryptocurrencies as "censorship resistance, transparency, and speed of trading". Above we have provided a simplified argument explaining that cryptocurrencies may have a value by offering features, such as anonymity of transactions, not covered by traditional currencies. Many findings, also those included in this special issue, point towards the intangible nature of the cryptocurrency value. Knowing more about it, we would be better equipped to understand the price dynamics and, reciprocally, the price dynamics would improve our understanding of decisions made by investors. So far, we remain very much agnostic in this respect.

The third issue is the societal role of cryptocurrencies and their regulation. While many discussions of cryptocurrencies stress that they are free of regulation, and the desire to be unregulated was one of drivers behind their creation, there is considerable controversy both about the application of existing regulation to cryptocurrencies and other cryptoassets and also what if any new regulations may be needed to protect investors, prevent financial crime and ensure financial stability. Are crypto investments securities and therefore subject to securities law (in the US this has been determined by the so-called Howey test)? What about the regulation of cryptoexchanges and the problems of hacking with some prominent examples of theft and failure to enforce "know-your-customer" (KYC) and anti-money-laundering (ALM) regulations?

\footnotetext{
14 It may matter though for the decision to mine new coins (the marginal cost of coin production should be below market price, which stands for the marginal profit). Hayes (2017) also points at the difficulty of the mining algorithm as a driver of cryptocurrency prices. This measure may be an indicator of the reliability of the cryptographic technology behind the cryptocurrency, and thus part of the fundamental value, as it represents security of transactions, valued by the users.
} 
Globally, regulators are shifting towards a tougher stance. Some exchanges are seeking to engage with regulators and be fully compliant. Others prefer to operate outside of regulation. A simple argument is that one has to protect investors and users from financial and technological risks they face. However, as papers presented in this special issue demonstrate, cryptocurrencies differ from traditional assets, hence the validity of traditional arguments, such as systemic stability, consumer protection and promotion of competition, is not clear. As our literature review and papers in this special issue underscore, cryptocurrencies do not comove with other assets; they help diversification and do not pose an immediate danger for systemic stability. There appears to be a significant and growing degree of competition between different cryptocurrencies and cryptoexchanges, and yet we have to understand whether and why such a competition is desirable for the society.

Similarly, we need to understand whether there is a need to protect consumers. In traditional asset markets and in banking such protection improves allocation of resources and promotes economic growth and welfare, which is not straightforwardly applicable to cryptocurrencies and existing other cryptoassets. An extra dimension that arises from the studies in our special issue is the sustainability and environmental impact of cryptocurrencies, and this is again different from other asset classes.

Last but not the least, yet another major issue is how cryptocurrency technologies may affect conventional fiat currency issued by central banks. ${ }^{15}$ Emerging literature on the competition between cryptocurrencies and fiat money raises concerns that the emergence of privately issued cryptocurrencies could weaken the monetary policy tools employed by the central bank and result in welfare losses (Zhu and Hendry 2018; Schilling and Uhlig 2019). Fernández-Villaverde and Sanches (2019) find that when private currency competes with a central bank issued e-money the former should vanish in equilibrium, yet it remains unclear what happens if cryptocurrencies are not a perfect substitute to fiat money. ${ }^{16}$ Cukierman (2019), building on the analysis by Roubini (2018), brings the discussion to a further level by discussing the potential also for cryptocurrency issue by the central bank being used to implement fully reserved or narrow banking and thus to promote financial stability.

We hope this special issue contributes to our understanding of cryptocurrencies and surrounding issues. We also reckon it helps generate knowledge and materials useful for practitioners and scholars, involved in studying and shaping the cryptocurrency market for the future. Very possibly this will evolve and become very different from what we observe today, but for sure already now cryptocurrencies embody an innovation capable of moving our financial markets and economies forward in terms of efficiency and growth. We just need to learn using this innovation properly.

\footnotetext{
15 Pieters (2020, forthcoming) provides a useful wider review of central banks and digital payments technologies.

${ }^{16}$ Fernández-Villaverde and Sanches (2019) also advance an interesting idea that cryptocurrencies, being "private money", create limits for monetary policy and, at the same time, provides market discipline for the government.
} 


\section{Compliance with ethical standards}

Conflict of interest On behalf of all authors, the corresponding author states that there is no conflict of interest.

\section{References}

Adhami, S., Giudici, G., \& Martinazzi, S. (2018). Why do businesses go crypto? An empirical analysis of initial coin offerings. Journal of Economics \& Business, 100, 64-75.

Adhami, S. \& Guegan, D. (2020). Crypto assets: the role of ICO tokens within a well-diversified portfolio. Journal of Industrial \& Business Economics (forthcoming).

Admati, A. R., \& Pfleiderer, P. (1988). A theory of intraday patterns: Volume and price variability. The Review of Financial Studies, 1(1), 3-40.

Akyildirim, E., Corbet, S., Katsiampa, P., Kellard, N., \& Sensoy, A. (2019). The development of Bitcoin futures: Exploring the interactions between cryptocurrency derivatives. Finance Research Letters. https://doi.org/10.1016/j.frl.2019.07.007. (in press).

Andersen, T. G. (1996). Return volatility and trading volume: An information flow interpretation of stochastic volatility. The Journal of Finance, 51(1), 169-204.

Azar, O. H. (2007). The slowdown in first-response times of economics journals: Can it be beneficial? Economic Inquiry, 45(1), 179-187.

Baek, C., \& Elbeck, M. (2015). Bitcoins as an investment or speculative vehicle? A first look. Applied Economics Letters, 22(1), 30-34.

Baliga, A. (2017). Understanding Blockchain Consensus Models. Persistent White paper. https://pdfs. semanticscholar.org/da8a/37b10bc1521a4d3de925d7ebc44bb606d740.pdf. Accessed 14 Sept 2019.

Bank of England, Financial Conduct Authority, and HM Treasury. (2018). Cryptoassets taskforce: Final report. London.

Baur, D. G., Hong, K., \& Lee, A. D. (2018). Bitcoin: Medium of exchange or speculative assets? Journal of International Financial Markets, Institutions and Money, 54, 177-189.

Bessembinder, H., \& Seguin, P. J. (1993). Price volatility, trading volume, and market depth: Evidence from futures markets. Journal of financial and Quantitative Analysis, 28(1), 21-39.

Blandin, A., Cloots, A. S., Hussain, H., Rauchs, M., Saleuddin, R., Allen, J. G., et al. (2019). Global cryptoasset regulatory landscape study. Cambridge: Cambridge Centre for Alternative Finance.

Böhme, R., Christin, N., Edelman, B., \& Moore, T. (2015). Bitcoin: Economics, technology, and governance. Journal of Economic Perspectives, 29(2), 213-238.

Bolt, W., \& Van Oordt, M. R. (2019). On the value of virtual currencies. Journal of Money, Credit and Banking. https://doi.org/10.1111/jmcb.12619.

Bouri, E., Molnár, P., Azzi, G., Roubaud, D., \& Hagfors, L. (2017). On the hedge and safe haven properties of Bitcoin: Is it really more than a diversifier? Finance Research Letters, 20, 192-198.

Caballero, R. J., \& Krishnamurthy, A. (2008). Collective risk management in a flight to quality episode. The Journal of Finance, 63(5), 2195-2230.

Cheah, E.-T., \& Fry, J. (2015). Speculative bubbles in bitcoin markets? An empirical investigation into the fundamental value of bitcoin. Economics Letters, 130, 32-36.

Corbet, S., Lucey, B., Urquhart, A., \& Yarovaya, L. (2019). Cryptocurrencies as a financial asset: A systematic analysis. International Review of Financial Analysis, 62, 182-199.

Corbet, S., Meegan, A., Larkin, C., Lucey, B., \& Yarovaya, L. (2018). Exploring the dynamic relationships between cryptocurrencies and other financial assets. Economics Letters, 156, 28-34.

Côté, A. (1994). Exchange rate volatility and trade. Bank of Canada.

Cukierman, A. (2019) Welfare and political economy aspects of a central bank digital currency. Centre for Economic Policy Research, discussion paper DP13728, May 2019.

Devenow, A., \& Welch, I. (1996). Rational herding in financial economics. European Economic Review, 40(3-5), 603-615.

Dow, J., \& da Costa Werlang, S. R. (1992). Uncertainty aversion, risk aversion, and the optimal choice of portfolio. Econometrica: Journal of the Econometric Society, 60(1), 197-204.

Dwyer, G. P. (2015). The economics of bitcoin and similar private digital currencies. Journal of Financial Stability, 17, 81-91. 
EBA. (2019). Report with Advice for the European Commission on crypto-assets. https://eba.europa.eu/ documents/10180/2545547/EBA+Report+on+crypto+assets.pdf. Accessed 14 Sept 2019.

ESMA. (2019). "Advice: Initial coin offerings and crypto-assets. https:/www.esma.europa.eu/sites/defau 1t/files/library/esma50-157-1391_crypto_advice.pdf. Accessed 14 Sept 2019.

Fantazzini, D., \& Zimin, S. (2020). A multivariate approach for the joint modelling of market risk and credit risk for cryptocurrencies. Journal of Industrial \& Business Economics (this issue).

FCA. (2019). Guidance on cryptoassets feedback and final guidance to CP 19/3. Policy Statement PS19/22. Financial Conduct Authority July 2019.

Fernández-Villaverde, J., \& Sanches, D. (2019). Can currency competition work? Journal of Monetary Economics, in press, . https://doi.org/10.1016/j.jmoneco.2019.07.003.

Figà-Talamanca, G., \& Patacca M. (2020). Disentangling the relationship between Bitcoin and market attention measures. Journal of Industrial \& Business Economics (this issue).

Foley, S., Karlsen, J., \& Putnins, T. (2019). Sex, drugs, and bitcoin: How much illegal activity is financed through cryptocurrencies? Review of Financial Studies, 32(5), 1798-1853.

Foster, F. D., \& Viswanathan, S. (1993). Variations in trading volume, return volatility, and trading costs: Evidence on recent price formation models. The Journal of Finance, 48(1), 187-211.

FSB. (2018). Crypto-asset markets Potential channels for future financial stability implications (p. 10). Basel: Financial Stability Board.

Gandal, N., Hamrick, J. T., Moore, T., \& Oberman, T. (2018). Price manipulation in the Bitcoin ecosystem. Journal of Monetary Economics, 95, 86-96.

Giudici, G., \& Adhami, S. (2019). The governance of ICO projects: Assessing the impact on fundraising success. Journal of Industrial and Business Economics, 46(2), 283-312.

Giudici, G., \& Paleari, S. (2000). The provision of finance to innovation: A survey conducted among Italian technology-based small firms. Small Business Economics, 14(1), 37-53. https://doi. org/10.1023/A:1008187416389.

Glaser, F., Zimmermann, K., Haferkorn, M., Weber, M. C., \& Siering, M. (2014). Bitcoin-asset or currency? revealing users' hidden intentions. Revealing Users' Hidden Intentions (April 15, 2014). ECIS.

Goldstein, I., Wei Jiang, W., \& Karolyi, G. A. (2019). To FinTech and Beyond. The Review of Financial Studies, 32(5), 1647-1661. https://doi.org/10.1093/rfs/hhz025.

Hacker, P., \& Thomale, S. (2017). Crypto-securities regulation: ICOs, token sales and cryptocurrencies under EU financial law. European Company and Financial Law Review, 15(4), 645-696.

Hayes, A. S. (2017). Cryptocurrency value formation: an empirical study leading to a cost of production model for valuing bitcoin. Telematics and Informatics, 34(7), 1308-1321.

Haryanto, S., Subroto A., \& Ulpah M. (2020). Disposition effect and herding behavior in the cryptocurrency market. Journal of Industrial \& Business Economics (this issue).

Hileman, G., \& Rauchs, M. (2017). Global cryptocurrency benchmarking study. Cambridge Centre for Alternative Finance. https://cdn.crowdfundinsider.com/wp-content/uploads/2017/04/Global-Crypt ocurrency-Benchmarking-Study.pdf. Accessed 14 Sept 2019.

Howell, S. T., Niessner, M., \& Yermack, D. (2018). Initial coin offerings: Financing growth with cryptocurrency token sales (No. w24774). National Bureau of Economic Research.

Huisman, J., \& Smits, J. (2017). Duration and quality of the peer review process: The author's perspective. Scientometrics, 113(1), 633-650.

Kahneman, D., \& Tversky, A. (1979). Prospect theory: An analysis of decision under risk. Econometrica, 47(2), 263-292.

Karlstrøm, H. (2014). Do libertarians dream of electric coins? The material embeddedness of bitcoin. Scandinavian Journal of Social Theory, 15(1), 25-36.

Liu, Y., \& Tsyvinski, A. (2018). Risks and returns of cryptocurrency (No. w24877). National Bureau of Economic Research.

Milne, A. (2015). Central securities depositories and securities clearing and settlement: Business practice and public policy concern. In M. Diehl, B. Alexandrova-Kabadjova, R. Heuver, \& S. MartínezJaramillo (Eds.), Analyzing the economics of financial market infrastructures. Hershey: IGI Global.

Milne, A. K. L. (2018) Argument by False analogy: The mistaken classification of Bitcoin as token money (November 25, 2018). https://ssrn.com/abstract=3290325.

Moosa, I. (2020). The Bitcoin: A Sparkling Bubble or Price Discovery? Journal of Industrial \& Business Economics (this issue).

Nakamoto, S. (2008). Bitcoin: a peer-to-peer electronic cash system. https://bitcoin.org/bitcoin.pdf. Accessed 14 Sept 2019. 
Narayanan, A., Bonneau, B., Felten, E., Miller, A., \& Goldfeder, S. (2016). Bitcoin and cryptocurrency technologies: A comprehensive introduction. Princeton: Princeton University Press.

OECD. (2019). Initial coin offerings (ICOs) for SME financing, http://www.oecd.org/finance/initial-coinofferings-for-sme-financing.htm.

Pieters, G. (2020). Central banks and digital currencies. In R. Rau, R. Wardrop, \& L. Zingales (Eds.), The Palgrave handbook of alternative finance. Basingstoke: Palgrave MacMillan.

Pilkington, M. (2016). Blockchain technology: Principles and applications. In F. Xavier Olleros \& M. Zhegu (Eds.), Research handbooks on digital transformations (pp. 225-253). Cheltenham: Edward Elgar.

Raiborn, C., \& Sivitanides, M. (2015). Accounting issues related to Bitcoins. Journal of Corporate Accounting \& Finance, 26(2), 25-34.

Ricci, P. (2020). How economic freedom reflects on the Bitcoin transaction network. Journal of Industrial \& Business Economics (this issue).

Richter, C., Kraus, S., \& Bouncken, R. C. (2015). Virtual currencies like Bitcoin as a paradigm shift in the field of transactions. International Business \& Economics Research Journal, 14(4), 575-586.

Roubini, N. (2018). Exploring the cryptocurrency and blockchain ecosystem. Washington, DC: Testimony for the Hearing of the US Senate Committee on Banking, Housing and Community Affairs.

Schilling, L., \& Uhlig, H. (2019). Some simple bitcoin economics. Journal of Monetary Economics (forthcoming).

Shefrin, H., \& Statman, M. (1985). The disposition to sell winners too early and ride losers too long: Theory and evidence. The Journal of Finance, 40(3), 777-790.

Shepherd, G. B. (1995). Rejected: Leading economists ponder the publication process. Sun Lakes: T. Horton and Daughters.

Shiller, R. J. (2003). From efficient markets theory to behavioral finance. Journal of Economic Perspectives, $17(1), 83-104$.

Siegel, J. J. (2003). What is an asset price bubble? An operational definition. European Financial Management, 9(1), 11-24.

Trueman, B. (1994). Analyst forecasts and herding behavior. The Review of Financial Studies, 7(1), 97-124.

Tschorsch, F., \& Scheuermann, B. (2016). Bitcoin and beyond: A technical survey on decentralized digital currencies. IEEE Communications Surveys and Tutorials, 18(3), 2084-2123.

Urquhart, A. (2016). The inefficiency of Bitcoin. Economics Letters, 148(1), 80-82.

Vaz, J., \& Brown, K. (2020). Sustainable development and cryptocurrencies as private money. Journal of Industrial \& Business Economics (this issue).

Vinogradov, D. (2012). Destructive effects of constructive ambiguity in risky times. Journal of International Money and Finance, 31(6), 1459-1481.

WEF. (2018). Trade Tech-A new age for trade and supply chain finance, The World Economic Forum in collaboration with Bain \& Company. World Economic Forum, January 2018. http://www3.wefor um.org/docs/White_Paper_Trade_Tech_report_2018.pdf. Accessed 14 Sept 2019.

Zhu, Y., \& Hendry, S. (2018). A framework for analyzing monetary policy in an economy with e-money (December 31, 2018). https://ssrn.com/abstract=3318915 or http://dx.doi.org/10.2139/ssrn.33189 15. Accessed 14 Sept 2019.

Publisher's Note Springer Nature remains neutral with regard to jurisdictional claims in published maps and institutional affiliations. 